This paper has been published in Current Opinion In Psychology, 2017, 15: 45-49.

DOI:10.1016/j.copsyc.2017.02.001

\title{
Protective Parenting: Neurobiological and behavioral dimensions
}

\author{
Marian J. Bakermans-Kranenburg ${ }^{12}$ \& Marinus H. van IJzendoorn ${ }^{123}$ \\ Centre for Child \& Family Studies \\ Leiden University \\ the Netherlands
}

${ }^{1}$ Centre for Child and Family Studies, Leiden University, the Netherlands
${ }^{2}$ Leiden Institute for Brain and Cognition, Leiden University, the Netherlands
${ }^{3}$ Center for Moral Socialization Studies, Erasmus University Rotterdam, the Netherlands

Key words: protection, sensitivity, morning sickness, oxytocin, fathers

We grateful acknowledge the support of the European Research Council (ERC AdG, MJBK), and the Netherlands Organization for Scientific Research (Spinoza, MHvIJ), as well as the Gravitation program of the Dutch Ministry of Education, Culture, and Science and the Netherlands Organization for Scientific Research (NWO grant number 024.001.003). Correspondence: Marian BakermansKranenburg, Leiden University, Centre for Child \& Family Studies, P.O. Box 9555, 2300 RB Leiden, the Netherlands; bakermans@fsw.leidenuniv.nl. 


\begin{abstract}
The current review focuses on a dimension of parenting that has largely been neglected in studies on human parenting, namely parental protection. Human protective parenting can be observed already during pregnancy, when mothers experiencing morning sickness avoid foods that are likely to carry pathogens and thus could be harmful to the fetus. After the birth of the baby, one of the foremost anxieties of parents is that their child will be abused or killed by strangers. Protective parenting seems to be a species-wide evolutionary based behavior complementary to the innate bias of each newborn to strive for proximity to a potentially protective attachment figure. Most important target for future work might be to describe, explain and uncover the correlates and consequences of individual differences in the quality of protection -in parents and other caregivers.
\end{abstract}

Highlights:

*Protective parenting is an important but neglected part of parenting

*Infant attachment behavior and protective parenting are complementary phenotypes rooted in evolution, in non-human animals as well as in the human species

*Prenatal protective parenting is visible in intuitive pathogen avoidance during pregnancy

*Oxytocin stimulates protective parenting in mothers

*Protective parenting is a multidimensional construct to be studied from an interdisciplinary perspective 


\section{Protective parenting}

One of the central constructs in parenting during infancy and the early childhood years is sensitive responsiveness or, shortly, sensitivity. Parental sensitivity has been defined as the parent's ability to notice child signals, interpret these signals correctly, and respond to these signals promptly and appropriately [1]. Sensitivity has been linked to secure infant-parent attachment [2] and more positive child developmental outcomes in various domains [3]. Another well-studied dimension of parenting concerns parental discipline, which becomes increasingly important when sweet babies turn into terrible toddlers. Negative control and harsh discipline, as well as laxness and a lack of monitoring are associated with more child behavior problems than gentle but firm discipline and an authoritative parenting style [4, 5]. Coercive cycles [6] and other transactional processes [7] may mediate these associations.

The current review focuses on a dimension of parenting that has largely been neglected in studies on human parenting, namely parental protection. This is remarkable since in the environment of evolutionary adaptedness selection may have favored infants' attachment behaviors just because these behaviors are shown when the infant is distressed or anxious, and elicit protection from parents or other caregivers $[8,9]$. The crucial role of protective parenting is most evident when it is absent: Parental neglect is a clear-cut example of lack of protection, and physical abuse is the opposite of parental protection. Both peak in early childhood, when protection is most needed.

\section{Non-human studies}

In non-human animals, protection of offspring is part and parcel of the task of new parents. Female chimpanzees with dependent infants keep their offspring close in the presence of males, because chimpanzee males show no mercy to infants that are not theirs [10]. In rodents, attacking intruders and retrieving pups that move away from the litter are considered signs of good parenting [11-14]. Oxytocin plays a critical role in these behaviors [15]: When a Wistar rat dam with her pups is confronted with an intruder, the dam's offensive attacks are positively related to her oxytocin levels. The intensity of maternal aggression increases to a maximum during early lactation, around days 4 to 7 , and disappears at weaning. This aggression curve has the same shape as the curve of oxytocin levels: oxytocin receptor binding in the lateral septum correlates with the peak of maternal aggression to intruders [16].

Moreover, the dam's high oxytocin levels after parturition support the detection and avoidance of disease-infected peers [17]. Female mice and prairie voles treated with an OT antagonist could no longer discriminate between the odors of healthy and infected males $[17,18]$. This suggests that oxytocin is part of the central mechanisms linking olfactory input to avoidance of infected conspecifics, which is important to protect offspring from pathogens.

\section{Protection in human parenting}

Human protective parenting does not start after birth, but can be observed already during pregnancy. Mothers are well-equipped protectors during pregnancy even if most pregnant females do not recognize their morning sickness or aversion from specific foods as 'protective pathogen avoidance'. Pregnant mothers tend to avoid foods that are likely to carry pathogens, in particular meat [19], that can be harmful in the first trimester of the pregnancy, when the fetus is without key immune defenses. A cross-cultural study showed higher rates of morning sickness in countries with higher consumption of foods that could harm the fetus [20]. This sickness, and the concomitant lower maternal food intake, peaks during the early pregnancy weeks with low caloric demands, so does not harm the growth of the fetus [21]. Actually, children of mothers with pregnancy sickness may have 
slightly more positive health outcomes than children of mothers without pregnancy sickness [22, 23], although effect sizes are very small $(d<0.10)$.

The instinctive avoidance of harmful pathogens during pregnancy is not limited to food. When shown male faces varying in apparent health (e.g., pallor), pregnant women preferred healthy faces to a larger extent $(d=0.28)$ than non-pregnant women [24]. Apparently, pregnant women are more sensitive to cues of ill health that should be avoided to protect their developing fetus. Oxytocin may play a role in this context, as it does in rodents. Human mothers show a pattern of gradual rise of oxytocin levels with advancing gestation and peak values after birth [25]. Therefore, the protective recognition of illness in others, boosted by oxytocin, may increase during pregnancy and be particularly relevant after birth, during the first weeks of the infant's vulnerable life. Further evidence for the role of oxytocin in the awareness and avoidance of potentially harmful filth comes from a study in which OT administration led to increased salience of faces expressing disgust [26].

Protective parenting goes however beyond the avoidance of pathogens. Human history is fraught with attacks by strangers on children and infanticide happened frequently [27]. Stranger anxiety, which begins to develop around the time that infants start to crawl, is universal and may be an evolved mechanism stimulating caution towards strangers [28]. For young children, therefore, parental protection was a matter of life and death. Even today, one of the foremost anxieties of parents is that their child will be abused or killed by strangers [29, 30], although in reality homicide accounts for less than $1 \%$ of actual harm to children nowadays. The fear of attack by conspecifics thus seems to reflect a primordial parental worry. Male strangers are feared by both adults and infants [31-33], even if the primary caregivers are male, so the aversion does not follow from mere unfamiliarity of males [34].

Studies on parental protection in response to cues of potential danger are scarce and have mostly involved mothers [35]. Mothers may be expected to be more focused on protection of offspring than fathers, given human mothers' higher investment in pregnancy, child birth, and breast-feeding. Nevertheless, fathers do play a critical role in the protection of offspring, as evident from the two-fold increase of the likelihood of child death in traditional societies when the father is absent [36]. These numbers may be smaller in modern society, but they underscore the plausibility that fathers, not unlike mothers, have the neurobiological equipment [37] and the innate tendency to protect their infants - in particular when they are convinced that they are their biological fathers.

\section{Protection strategies: tend-and-befriend or tend-and-defend}

In a seminal paper, Shelley Taylor and her colleagues (2000) proposed the tend-and-befriend model as the maternal alternative to the fight-or-flight model of male behavioral responses to stress [38]. Tending, the protection and care of offspring, and befriending, the formation and maintenance of interpersonal relationships with conspecifics, were proposed as strategies that females use in times of stress to defend themselves and their offspring. Aggression in response to stress would be nonadaptive for females -- they would expose their offspring to great risk if they could not, in times of threat, depend on their social network. A central role in the tend-and-befriend model is attributed to oxytocin, which provides the neuroendocrine basis for affiliation with social groups. In monkeys and apes this strategy of sociability to increase the safety of their offspring leads to drastic measures: females mate with several males to increase the number of protectors of their infant - primate males will protect offspring that might be theirs [27]. Taylor argues that in human males, the common stress response would be characterized by fight or flight, activated by androgens [38]. The tend-and-befriend model would not be applicable due to males' low levels of oxytocin and estrogen [39], while testosterone antagonizes affiliation [40]. However, paternal testosterone levels decrease after birth [41] while oxytocin levels increase [12], which may enhance their protective parenting behaviors. 
Important questions for further research on protective parenting are the following: (1) What strategies do modern parents use to protect their offspring: tend-and-befriend (use of social relationships for protection) or tend-and-defend (aggression against the threatening stimulus)? (2) Are these strategies different for mothers and fathers, or are they more dependent on the environmental (harsh or benign) context? (3) Is protective parenting behavior influenced by hormone levels? (4) Is the variance in parental protective behaviors meaningfully related to other parenting behaviors and to child development? Although one may be inclined to think that anxious parents may be the most protective parents, this is probably not the case. Highly anxious parents may be overwhelmed by cues of threat and freeze rather than protect their offspring, not unlike their being overwhelmed by infant distress $[42,43]$. The overlap and differences between protective parenting on the one hand and parental sensitivity and discipline on the other hand are important avenues for further research.

\section{A measure of protective parenting}

The observation of protective parenting in an ecologically valid way presents a puzzle. The use of real threats is ethically unacceptable. For the observation of protective parenting, we developed the Enthusiastic Stranger Paradigm [44]. While sitting in a waiting room with the infant on the floor at some distance from its parent, an unknown adult (the 'Stranger') enters the room. The stranger apologizes for the interruption and pretends to be present for the purposes of a work related reason (e.g., checking smoke detectors). Soon after entering, the stranger notices the infant, makes a comment ("What a lovely baby") and then moves toward the infant, without seeking verbal nor nonverbal permission from the mother, but alert to any resistance from the part of the parent. The stranger attempts to engage the baby, aiming to elicit a number of smiles, with increasing levels of intrusiveness. In the final stage of the approach, the stranger touches the baby on the shoulder and cheek unless the parent interferes. The stranger then apologizes for the interruption and leaves the room.

We used the Enthusiastic Stranger Paradigm in a double-blind, randomized-controlled, withinsubject design with oxytocin and placebo administration in a group of mothers with a diagnosis of postnatal depression. Maternal protection was coded on a rating scale ranging from 1 (no or brief glances toward the stranger) to 5 (active and direct attempts to stop the stranger, using motor and/or verbal behavior). In the oxytocin condition mothers were significantly more protective of their baby in the presence of a stranger, independent of level of mothers' depression. Replication of our findings in fathers and non-depressed mothers is ongoing. We plan to have the stranger pick up the baby and carry it away to a corner of the room at the final stage of the paradigm, if the parent has not interfered earlier. This Enthusiastic Stranger Paradigm, taking no more than three minutes, may be an ethically acceptable procedure to assess protective parenting with high ecological validity: All parents know that neighbors and strangers alike peek into the pram to have a close-up of the baby and try to touch its cheeks. Of course, culture, ethnicity, and socio-economic status may affect parents' response to the Enthusiastic Stranger Paradigm which would provide information about environmental influences on protective parenting.

\section{Implications for future research and clinical practice}

Protective parenting seems crucial for offspring survival in animals as well as in humans, in harsh as well as benign environments. It is safe to conclude that in humans protective parenting is a species-wide evolutionary based phenotype complementary to the innate bias of each newborn to strive for proximity to a potentially protective attachment figure [45]. Most important target for future 
work might be to describe and explain the consequences of individual differences in the quality of protection -in parents and other caregivers. Of course, such work should be interdisciplinary, taking into account genetic, hormonal, neural, and behavioral determinants and concomitants of protective parenting.

A prerequisite of an interdisciplinary multilevel study of protective parenting however is the careful behavioral description and measurement of this complex phenotype, or rather of its phenotypic dimensions. Protective parenting might well be a multidimensional construct including dimensions such as neglect versus overprotection, proactive versus reactive protection, sensitive versus insensitive protection or exploration-promoting versus exploration-suppressing protection. See Figure 1 for a hypothetical dimensional structure of protective parenting. The sensitive parent may proactively guide the child through increasingly risky or dangerous situations serving as a scaffold for exploration, or gently turn the child away from imminent threats to his or her physical or psychological integrity, leaving the exploration of precursors of these challenging environments to trial-and-error. The insensitive parent may rely on reactively interfering with the child's behavior not before the child has put itself in danger (neglect), or proactively keep the child away from any risky situation at the expense of exploration (overprotection). Of course, parenting behaviors will differ depending on parents' dealing with babies or adolescents [46], but the same dimensions may be observable.

These dimensions might indeed turn out to be orthogonal as presented in the Figure, or they may be oblique, with different correlates and sequelae, or we may need more dimensions to cover the complexity of protective parenting. It is crucial for progress in this field to avoid premature closure on a single dimension, and to keep an open, multidimensional structure as a model at the fore-front of research.

Figure 1

A dimensional structure of protective parenting

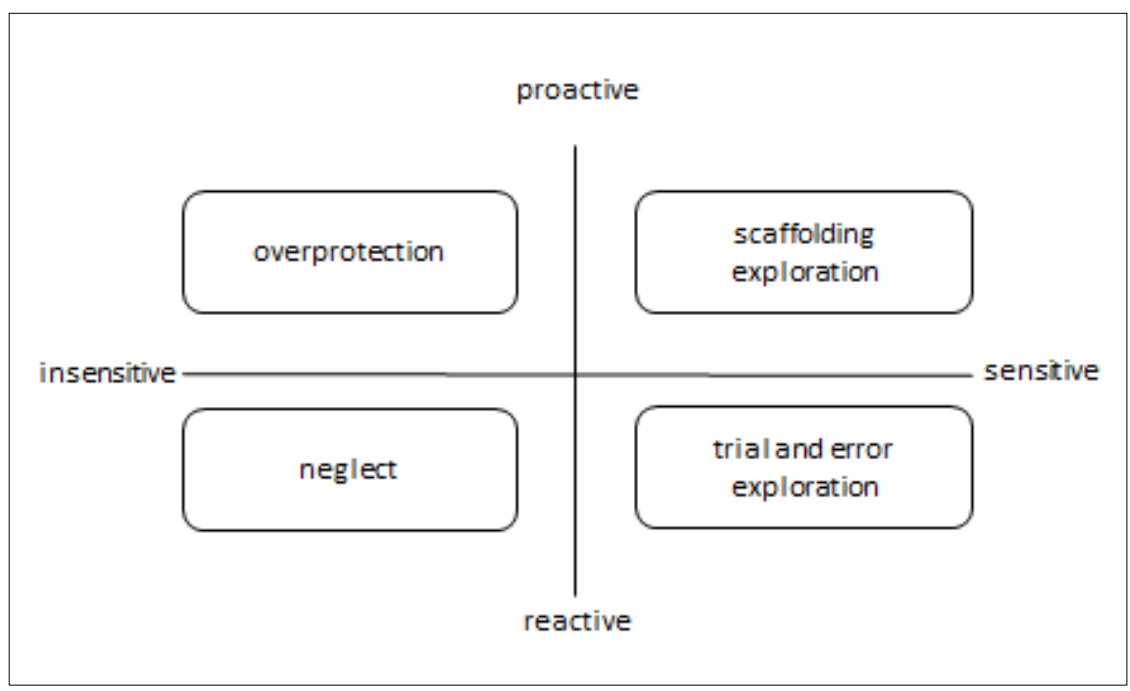


References

1. Ainsworth MDS, Bell S, Stayton D: Infant-mother attachment and social development. In The introduction of the child into a social world. Edited by Richards MP. Cambridge: University Press; 1974:99-135.

2. Bakermans-Kranenburg M J, Van IJzendoorn MH, Juffer F: Less is more: meta-analyses of sensitivity and attachment interventions in early childhood. Psychol bull 2003, 129:195-215.

3. Sroufe LA, Egeland B, Carlson EA, Collins WA: The development of the person. New York: Guilford; 2011.

4. Baumrind D: Parental disciplinary patterns and social competence in children. Youth Soc 1978, 9:239-276.

5. Kochanska G, Aksan N, Prisco TR, Adams EE: Mother-child and father-child mutually responsive orientation in the first 2 years and children's outcomes at preschool age: Mechanisms of influence. Child Dev 2008, 79:30-44.

6. Patterson GR: Coercive family process: A social learning approach. Eugene, Castalia; 1982.

7. Sameroff A: Transactional models in early social relations. Hum Dev 1975, 18:65-79.

8. Bowlby J: Attachment. Volume 1: Attachment and loss. Harmondsworth: Penguin Books; 1969/1989.

9. Simpson JA, Belsky J: Attachment theory within a modern evolutionary framework. In Handbook of attachment: Theory, research, and clinical applications. Edited by Cassidy J, Shaver PR. New York: Guilford Press; 2016.

10. Otali E, Gilchrist JS: Why chimpanzee (Pan troglodytes schweinfurthii) mothers are less gregarious than nonmothers and males: the infant safety hypothesis. Behav Ecol Sociobio 2006, 59:561-570.

11. Pedersen CA, Caldwell JD, Walker C, Ayers G, Mason GA: Oxytocin activates the postpartum onset of rat maternal behavior in the ventral tegmental and medial preoptic areas. Behav neurosci 1994, 108:1163.

12. Feldman R, Bakermans-Kranenburg,MJ: Oxytocin: A parenting hormone. Curr $O p$ in Psychol in press, this issue.

13. Knop J, Van der Veen R, Joëls M: The added value of rodent models in studying parental influences on offspring development: opportunitues, limitations and future perspectives. Curr Op in Psychol in press, this issue.

14. Bales KL: Parenting in animals. Curr Op in Psychol in press, this issue. 
15. Bosch OJ, Meddle SL, Beiderbeck DI, Douglas AJ, Neumann ID: Brain oxytocin correlates with maternal aggression: link to anxiety. J Neurosci 2005, 25:6807-6815.

16. Caughey SD, Klampfl SM, Bishop VR, Pfoertsch J, Neumann ID, Bosch OJ, Meddle SL: Changes in the intensity of maternal aggression and central oxytocin and vasopressin V1a receptors across the peripartum period in the rat. J Neuroendocrinol 2011, 23:1113-1124.

17. Kavaliers M, Choleris E, Ågmo A, Pfaff DW: Olfactory-mediated parasite recognition and avoidance: Linking genes to behavior. Horm Behav 2004, 46:272-283.

18. Arakawa $\mathrm{H}$, Arakawa $\mathrm{K}$, Deak T: Oxytocin and vasopressin in the medial amygdala differentially modulate approach and avoidance behavior toward illness-related social odor. Neurosci 2010, 171:1141-1151.

19. Flaxman SM, Sherman PW: Morning sickness: a mechanism for protecting mother and embryo. $Q$ Rev Biol 2000, 75:113-148.

20. Pepper GV, Roberts SC: Rates of nausea and vomiting in pregnancy and dietary characteristics across populations. P Roy Soc B-Biol Sci 2006, 273:2675-2679.

21. Fessler DMT: Reproductive immunosuppression and diet: an evolutionary perspective on pregnancy sickness and meat consumption. Curr Anthropol 2002, 43:19-39.

22. Furneaux EC, Langley-Evans AJ, Langley-Evans SC: Nausea and vomiting of pregnancy: endocrine basis and contribution to pregnancy outcome. Obstet Gynecol Surv 2001, 56:775-782.

23. Weigel MM, Reyes M, Caiza ME, Tello N, Castro NP, Cespedes S, Duchicela $\mathrm{S}$, Betancourt $\mathrm{M}$ : Is the nausea and vomiting of early pregnancy really fetoprotective? J Perinat Med 2006, 34:115-122.

24. Jones B, Perrett D, Little A, Boothroyd L, Cornwell RE, Feinberg DR, Tiddeman BP, Whiten S, Pitman RM, Hillier SG et al: Menstrual cycle, pregnancy and oral contraceptive use alter attraction to apparent health in faces. $P R$ Soc Lond B Bio 2005, 272:347-354.

25. De Geest K, Thiery M, Piron-Possuyt G, Van den Driessche R: Plasma oxytocin in human pregnancy and parturition. J Perinat Med 1985, 13:3-13.

26. Theodoridou A, Penton-Voak IS, Rowe AC: A direct examination of the effect of intranasal administration of oxytocin on approach-avoidance motor responses to emotional stimuli. Plos One 2013, 8:e58113.

27. **Hrdy SB: Mother Nature. Maternal instincts and how they shape the human species. New York: Ballantine; 1999.

A comprehensive treatise of parenting in a large variety of species, with an emphasis on several maternal strategies to protect offspring against natural dangers and male intruders. 
28. Hahn-Holbrook J, Holbrook C, Bering J: Snakes, spiders, strangers: how the evolved fear of strangers may misdirect efforts to protect children from harm. In Protecting Children from Violence: Evidence Based Interventions. Edited by Lampinen JM, SextonRadek K. New York: Psychology Press; 2010:263-289.

29. Kantrowitz B: Off to a good start. Newsweek 1997, 7:6-9.

30. Kidscape: How safe are our children? London: Kidscape; 1993.

31. Navarrete CD, Olsson A, Ho AK, Berry Mendes W, Thomsen L, Sidanius J: Fear extinction to an out-group face the role of target gender. Psychol Sci 2009, 20:155158.

32. Feinman S: Infant response to race, size, proximity, and movement of strangers. Inf Behav Dev 1980, 3:187-204.

33. Skarin K: Cognitive and contextual determinants of stranger fear in six-and elevenmonth-old infants. Child Dev 1977, 48:537-544.

34. Lamb ME, Hwang CP, Frodi AM, Frodi M: Security of mother-and father-infant attachment and its relation to sociability with strangers in traditional and nontraditional Swedish families. Inf Behav Dev 1982, 5:355-367.

35. **Hahn-Holbrook J, Holbrook C, Hasselton MG: Parental precaution: Neurobiological means and adaptive ends. Neurosci Biobehav Rev 2011, 35:1052-1066.

Parental precaution supports protection of offspring in several species. The authors review the role of reproductive hormones in alerting parents to danger and in stimulating a protective response.

36. Hurtado AM, Hill K: Parental effect on offspring survivorship among Ache and Hiwi hunter-gathers: implication for modeling pair-bonding stability. In Father-Child Relations: Cultural and Biosocial Contexts. Edited by Hewlett B. New York: Aldine de Gruyter; 1992.

37. Rilling JK, Mascaro JS: The Neurobiology of Fatherhood . Curr Op in Psychol in press, this issue.

38. *Taylor SE, Klein LC, Lewis BP. Biobehavioral responses to stress in females: tendand-befriend, not fight-or-flight. Pscychol Rev 2000, 107:411-429.

Highly influential review of the tend-and-befriend hypothesis as a 'female' complement to the dominant 'male' model of the fight-or-flight response to threat.

39. Taylor SE: The tending instinct: How nurturing is essential to who we are and how we live. New York: Holt; 2002.

40. Wright ND, Bahrami B, Johnson E, Di Malta G, Rees G, Frith CD, Dolan RJ: Testosterone disrupts human collaboration by increasing egocentric choices. Proc Biol Sci 2012, 279:2275-2280. 
41. Gettler LT, McDade TW, Feranil AB, Kuzawa CW: Longitudinal evidence that fatherhood decreases testosterone in human males. Proc Natl Acad Sci USA 2011, 108:16194-16199.

42. Riem MME, Bakermans-Kranenburg MJ, Van IJzendoorn MH, Out D, Rombouts SARB: Attachment in the brain: adult attachment representations predict amygdala and behavioral responses to infant crying. Att Hum Dev 2012, 14:533-551.

43. *Rilling JK: The neural and hormonal bases of human parental care. Neuropsychologia 2013, 51:731-747.

This review shows the convergence between brain system activations involved in parenting and in social cognition, and it suggests that optimal parenting might imply a mid-way between too low and too high physiological responsivity to child signals.

44. **Mah BL, Bakermans-Kranenburg MJ, Van IJzendoorn MH, Smith R: Oxytocin promotes protective behavior in depressed mothers: a pilot study with the enthusiastic stranger paradigm. Depression Anxiety 2014, 32:76-91.

This paper introduces the new Enthusiastic Stranger Paradigm to assess the influence of intranasally administered oxytocin on protective parenting of clinically depressed mothers towards their infants.

45. Fearon P, Roisman G: Attachment theory: progress and future directions. Curr Op in Psychol in press, this issue.

46. Kobak R: Adapting to the changing needs of adolescents: parenting practices and challenges to sensitive attunement. Curr Op in Psychol in press, this issue. 